\title{
El problema de las lenguas "prehistóricas". Un debate sobre el estudio de las lenguas indígenas a comienzos del siglo XX
}

The problem of "prehistoric" languages. A debate on the study of indigenous languages in the early 20th century

Luisa Domínguez

CONICET / Universidad de Buenos Aires, Argentina

domingluisa@gmail.com

\section{Resumen:}

Durante la primera mitad del siglo XX en Argentina, el problema del estudio de las lenguas indígenas fue un objeto delineado y absorbido por la americanística; sin embargo, hubo ocasiones en que fue disputado por el área de estudios lingüísticos. Esta tensión se refleja en un debate que comenzó en el diario La Prensa y que continuó en la revista cultural Nosotros entre 1928 y 1929. En él participaron Arturo Costa Álvarez, filólogo y traductor; José Imbelloni, antropólogo; un discípulo de este último, Enrique Palavecino, y el musicólogo y folklorólogo Carlos Vega. A partir de un exhaustivo trabajo de archivo, este artículo se propone relevar los principales tópicos que se abordan en el debate y vincularlos con un conjunto de discusiones contemporáneas en el ámbito local e internacional acerca del valor de la lingüística para los análisis culturales. Asimismo, el artículo busca problematizar qué implicancias tiene la inscripción de la lingüística indígena en el ámbito de la americanística y su relación con el desarrollo de la lingüística como ciencia, y arriesga algunas lecturas acerca de las posibles razones que permiten explicar esta particular distribución disciplinar.

Palabras Clave: Lenguas indígenas, Americanismo, Historia de la lingüística, Debates en la prensa.

\section{ABstract:}

During the first half of the 20th century in Argentina, the subject of indigenous languages was problematized and analyzed by Americanistic studies. However, on some occasions, the area of linguistics also disputed this object. This tension between disciplines is reflected in a debate that will be analyzed in this article. The discussion started in La Prensa, a very popular newspaper of those years, and continued in the cultural magazine Nosotros between 1928 and 1929. The participants in this debate were Arturo Costa Álvarez, philologist and translator; José Imbelloni, anthropologist; one of his disciples, Enrique Palavecino, and the musicologist and folklorologist Carlos Vega. The following paper aims to present the main topics of this dispute and link them with the discussions that were taking place on the value of linguistics for cultural analysis. Likewise, this paper problematizes the implications of the inscription of indigenous linguistics in the field of Americanistic studies, its relation to the development of linguistics as a science and risks the possible reasons that may explain this particular disciplinary distribution.

KEYWORDS: Indigenous languages, Americanistic studies, History of linguistics, Press debates.

Un martes de octubre del año 1928, Arturo Costa Álvarez publica una nota en el diario La Prensa, titulada "La lingüística al uso del arqueólogo", que inaugura una polémica acerca del abordaje de las lenguas indígenas en Argentina. En ella, el autor cuestiona el método aplicado para su estudio por los americanistas, quienes venían haciendo uso de un conjunto de saberes y categorías provenientes de la lingüística para establecer orígenes y parentescos entre distintos pueblos. La base de su crítica es un libro que José Imbelloni había publicado dos años antes: La Esfinge Indiana. Antiguos y nuevos aspectos de los orígenes del hombre americano (1926). En respuesta a esta nota, el primero en intervenir es el musicólogo y folklorólogo Carlos Vega, quien en 1928 lleva a cabo en la revista Nuestras escuelas una defensa del trabajo de los americanistas criticados por Costa Álvarez. Luego, se desencadena un debate en la revista cultural Nosotros donde intervienen, además de Costa Álvarez (1928b, 1929), Enrique Palavecino (1928a, 1928b, 1929), discípulo de Imbelloni y colaborador de la Esfinge; y el propio Imbelloni (1928).

A partir del análisis de este material, el presente trabajo se propone, por un lado, reflexionar acerca del lugar otorgado al estudio de las lenguas indígenas dentro del naciente campo científico argentino en las 
primeras décadas del siglo XX, en el marco de un proceso de "modernización de la cultura" mediante el cual comenzó a gestarse una división del trabajo intelectual y en el que la acción de las universidades y de la prensa fue fundamental para la profesionalización del conocimiento y la articulación de los intelectuales y un público lector no especializado (Bruno, 2012). Se profundizará, así, en el análisis de la posición de los agentes que intervienen en la polémica en relación con la creciente institucionalización del conocimiento científico, en el sentido de Bourdieu (2000 [1976]), como así también con las líneas teóricas y metodológicas en las que se basan. Con ello se busca caracterizar el estudio de estas lenguas en el periodo a nivel local y su relación con las tendencias de investigación en lingüística y antropología de las tradiciones europeas, donde también se estaban debatiendo cuestiones metodológicas sobre los parentescos lingüísticos (Baggioni, 1988); y norteamericanas, donde se estaba reflexionando sobre el carácter instrumental de la lingüística para el análisis de la cultura (Duranti, 2003). Por otra parte, el problema de la inscripción disciplinar del estudio de estas lenguas proyecta ciertas representaciones acerca de ellas y da cuenta del lugar histórico en que se ubicó a los pueblos americanos. En este sentido, este trabajo también se propone problematizar qué significa que sean antropólogos o americanistas, y no lingüistas o filólogos, quienes se encargaron de su estudio.

\section{CoRrelaCiONES LINGÜÍSTICAS}

José Imbelloni (1885-1967), especialista en antropología física, nacido y formado en Italia, llega a la Argentina a fines de 1920. Paulatinamente se va posicionando en el campo de la antropología de este país, lo que lo llevará a ocupar un lugar central que alcanzará promediando la década del treinta ${ }^{1}$. Entre 1921 y 1926, se desempeña como redactor de una columna dominical en el diario La Prensa,donde se encarga de la difusión de variados temas del americanismo y desde donde polemiza con otros intelectuales locales e internacionales (véase Mailhe, 2016). En la academia argentina, ocupa puestos de relevancia creciente: hacia 1928 es profesor suplente de Antropología en la Facultad de Filosofía de la Universidad de Buenos Aires, profesor titular de Historia de Roma y Edad Media en la Facultad de Ciencias de la Educación en la Universidad Nacional del Litoral y director técnico de la Biblioteca de la misma unidad académica; adscripto honorario y encargado de investigaciones antropológicas del Museo Etnográfico; miembro correspondiente de la Junta de Historia y Numismática Americana y adscripto ad honorem de la sección de Antropología del Museo Nacional de Historia Natural de Buenos Aires (Imbelloni, 1930).

En 1926, publica La Esfinge Indiana, una de sus primeras obras y, tal vez, una de las más ambiciosas. Con base en la teoría an tropológica germano-austríaca de la escuela histórico-cultural y en consonancia con uno de los problemas centrales de la antropología occidental del momento (Perazzi, 2009), este trabajo se encuentra vertebrado por dos interrogantes: "¿Quiénes son y de dónde vienen los indios que el europeo ha encontrado en América?” y “¿De qué manera ha contestado el hombre a la Esfinge Indiana desde el Renacimiento hasta el siglo XX?” (1926a: 17).

Este último interrogante de carácter teórico e historiográfico lo lleva a poner en cuestión distintas teorías de los principales referentes del americanismo, locales e internacionales, contemporáneos y anteriores ${ }^{2}$. Algunos de ellos son el antropólogo estadounidense Daniel Brinton (1837-1899), de gran influencia en el americanismo local; el glotólogo italiano defensor de la teoría monogenética del lenguaje humano, Alfredo Trombetti (1866-1929); o el especialista en el problema de las ruinas de Tiahuanaco, Arthur Posnansky (1873-1946), entre muchos otros.

Por su parte, el primer interrogante referido a la procedencia del hombre americano se funda en la hipótesis de que estos pueblos provienen de las islas de la Polinesia. En lo relativo a las lenguas, Imbelloni sostiene la idea de que "el Quechua es una lengua introducida al continente americano por inmigrados de Oceanía” (Imbelloni, 1926a: 357). La principal búsqueda de la escuela histórico-cultural y de gran parte de la antropología del periodo es la organización de tipologías raciales; en este plano, la lingüística, junto con el estudio de las culturas de los pueblos, son dos conocimientos básicos, ya que se parte del supuesto de 
que si hay coincidencias muy posiblemente se trate de un origen común. En la última parte de La Esfinge dedica un apartado, "Dos notas preliminares sobre el idioma quechua", al establecimiento de parentescos entre lenguas polinesias y americanas. La "addenda" -así introducida en el índice del libro- está integrada por dos artículos: el primero de ellos, "Elementos lingüísticos de Oceanía en el Quechua", a cargo de Palavecino, consiste en un vocabulario comparado de correlaciones lingüísticas entre el maorí y el quechua. Le sigue un artículo del propio Imbelloni, "El idioma de los Incas del Perú en el grupo lingüístico melanesio-polinesio", donde este expone la metodología aplicada por su discípulo. Allí plantea que "[y]a es tiempo de fundar la lingüística comparada de esas dos lenguas sobre una base científica. Desechamos por principio la indagación etimológica. Nuestros 'hechos' son: $1^{\circ}$ el glosario, $2^{\circ}$ el fonema y $3^{\circ}$ el morfema, en lo poco que consiente la escasa flexión de estas lenguas." (Imbelloni, 1926a: 354). Esta enumeración jerarquizada de los elementos que deben someterse a comparación será uno de los puntos con los que más abiertamente va a disentir Costa Álvarez dos años después.

La base de la que parte Imbelloni para anteponer el léxico de una lengua frente a la gramática son los trabajos del antropólogo francés Paul Rivet (1876-1958), quien recientemente había publicado dos artículos con una propuesta similar: "Les Mélanéso-Polynesiens et les Australiens en Amérique" (1924) y "Les origines de l'homme américain" (1925). Allí, Rivet propone vínculos filiatorios entre el grupo lingüístico hoka de América del Norte y la familia de lenguas melanesio-polinesia, por un lado, y el grupo tshon de la Patagonia argentina y las lenguas de Australia, por el otro, a partir de la comparación de elementos léxicos. El planteo de Rivet resulta innovador para Imbelloni porque propone una conexión intercontinental que rompe las barreras del Océano Pacífico y por el método multidisciplinar que aplica para sus análisis:

La importancia fundamental del descubrimiento de Rivet no consiste tan solo en haber roto el aislamiento idiomático del indígena americano, sino de haber comprobado que el camino metódico que debe seguirse no es ya la búsqueda desordenada de analogías lingüísticas en toda la extensión de América, simultáneamente, sino el estudio de aquellos grupos que la etnografía ya nos ha puesto en condición de clasificar, a base de su patrimonio instrumental o mental, del que, en definitiva, forma parte la misma lengua. Finalmente, las analogías etnográficas y lingüísticas deben ser confirmadas por el vínculo racial revelado por la somatología. (Imbelloni, 1926b: 36)

Otro de los puntos de partida tendientes al establecimiento de las correlaciones es el método Wörter und Sachen, gestado por el austríaco Rudolf Meringer (1859-1931) y el alemán Hugo Schuchardt (1842-1927):

Una segunda categoría de testimonios está constituida por los vocablos culturales (Kulturwörter), que demuestran, además de la puramente idiomática, la procedencia de instituciones, armas, costumbres, instrumentos y técnicas características. (Imbelloni, 1926a: 357)

Este método, basado en la categoría "Kulturwörter", implica considerar, entonces, no solo la historia de los términos como datos de la lengua, sino también la historia de los objetos que designan, en tanto estos permiten definir ciertos aspectos de las culturas sometidas a estudio (Calvo Calvo, 1991; Perna, 2007).

La correlación más conocida propuesta por Imbelloni (a la que dedicó varios artículos y fue discutida en más de una ocasión) es sobre el término término toki, 'hacha': 
TOKI, el hacha

\begin{tabular}{|l|l|l|l|l|l|l|l|l|}
\hline N. Zelandia & Samoa & Tonga & Tahiti & Marquesas & Rapa-nui & Perú & Chile & Patagonia \\
\hline toki & to'i & $\begin{array}{l}\text { toki-a- } \\
\text { tonga }\end{array}$ & toi & $\begin{array}{l}\text { to'i } \\
\text { toki } \\
\text { toki-mana, } \\
\text { hacha } \\
\text { sagrada } \\
\text { de mando }\end{array}$ & toki & toqui & $\begin{array}{l}\text { toqui } \\
\text { toquitu } \\
m, \\
\text { hachar }\end{array}$ & toqui \\
\hline
\end{tabular}

Fuente: Imbelloni, 1926a: 352

En función del cuadro, se aprecia que las correlaciones consisten en la identificación de la distribución geográfica de términos similares fonética y semánticamente pertenecientes a lenguas habladas en diferentes regiones. Los datos son extraídos de distintas fuentes escritas y, posteriormente, sometidos a comparación. En este caso, las principales referencias son los diccionarios de Herbert Williams de 1917 sobre el maorí y el de Ernst Middendorf de 1890 sobre el quechua.

\section{EL DEBATE}

Arturo Costa Álvarez (1870-1929) fue una de las figuras más relevantes en los estudios lingüísticos argentinos de las dos primeras décadas del siglo XX. Traductor de "todas las lenguas oficiales de América y Europa" -tal como reza su placa publicitaria que se conserva en su archivo en la Biblioteca Pública de la Universidad Nacional de La Plata-, redactor de La Prensa y La Nación y autor de Nuestra lengua (1922) y El castellano en Argentina (1928), es a la vez un destacado polemista que participa en los principales periódicos del momento con discusiones sobre el español, los alcances de la lingüística como disciplina en formación y sobre su institucionalización y profesionalización. El debate que inicia con la publicación de "La lingüística al uso del arqueólogo" en La Prensa forma parte de una serie de polémicas que sostuvo con distintos especialistas en lingüística y materias afines que vienen siendo objeto de abordaje por la crítica en los últimos tiempos (Degiovanni y Toscano y García, 2010; Alfón, 2011; Ennis, 2012; Toscano y García, 2005, 2013a), debido a la diversidad de oponentes y aspectos lingüísticos a los que se enfrenta en un espacio de gran difusión como lo era la prensa gráfica a comienzos del siglo XX.

En este artículo, Costa Álvarez se centra en La Esfinge para cuestionar el método aplicado por los americanistas, entre los cuales también incluye a Rivet, para el establecimiento de las correlaciones lingüísticas. Para Costa Álvarez el problema de los "arqueólogos" es que basan sus hipótesis filogenéticas en coincidencias léxicas, que no son pruebas fidedignas de la comunidad de origen. El punto de partida de su argumentación es el trabajo de Antoine Meillet (1866-1936), a quien considera "la última palabra de la ciencia" ${ }^{3}$. Un tiempo antes, Meillet $(1913,1924)$ había propuesto una jerarquización de los elementos de las lenguas sometidas a comparación para el establecimiento de vínculos genéticos más precisos. Así, el principal plano a compararse, según Meillet, debía ser el gramatical, ya que las coincidencias fonéticas y, más aún, las léxicas podían explicarse por otro tipo de procesos como el contacto, tratándose, por lo general, de casos de préstamo.

Otra de las críticas de Costa Álvarez se refiere a los elementos presentes en el vocabulario de Palavecino. Al respecto, plantea que "las analogías gráficas que ese trabajo expone pueden ser como no ser analogías fónicas", y que "las aproximaciones semánticas de los vocablos relacionados son, por lo general, demasiado latas para 
que puedan ser tenidas por correspondencias" (1928a: 15). Además, cuestiona el uso que hace Imbelloni de la terminología lingüística, ya que confunde "fonema" por "dicción", "glosario" por "vocabulario", etc. Ambas críticas le permiten construir el argumento de que estos intelectuales desconocen, ya no las últimas tendencias europeas en lingüística, sino las nociones básicas de la disciplina. Las palabras de cierre de la nota en cuestión son elocuentes para establecer una mirada más general del asunto: "Está visto que la lingüística es en la obra de los americanistas un simple puntal de arrimo, que se alarga, se acorta, se tuerce y se endereza, para adaptarse al uso del arqueólogo" (1928a: 15).

El debate continúa a partir de varias intervenciones. Luego de esta nota de Costa Álvarez en La Prensa, Carlos Vega publica, en la revista Nuestras escuelas, un descargo en defensa de los americanistas que no será retomado por ninguno de los demás participantes (Vega, 1928); volveremos, más adelante, a este artículo. En lo sucesivo, la polémica tomará lugar en Nosotros, una revista cultural en la que, desde sus primeros números, tuvieron lugar importantes debates acerca de la lengua como elemento clave para la definición de la identidad nacional (véase Di Tullio, 2003; Sesnich, 2014). Palavecino interviene con un artículo titulado "Los orígenes americanos y la lingüística" (1928a), que integra el temario principal del número 233 de la revista. Inmediatamente responde Costa Álvarez, con un descargo publicado en la sección "Notas y comentarios" (es decir, no será uno de los artículos principales del número), donde esgrime los mismos argumentos que los expuestos en el primer artículo (Costa Álvarez, 1928b). Imbelloni participa, por su parte, en el número 235 con un artículo titulado "Etnología y lingüística" (1928a), que forma parte de los trabajos principales de ese número; allí también, Palavecino vuelve a intervenir, otra vez en la sección de "Notas y comentarios" (Palavecino, 1928b). A comienzos de 1929, Costa Álvarez arremete una vez más (Costa Álvarez, 1929). El debate finaliza con una última nota de Palavecino (1929). A continuación, se abordarán los aspectos más relevantes de las intervenciones.

Enrique Palavecino (1900-1966) al momento se encontraba en su etapa de formación como antropólogo bajo la supervisión de Imbelloni. En defensa de sus hipótesis genéticas, se basa en los planteos de reconocidos antropólogos y etnógrafos de la época: Georg Friederici (1866-1947), Robert Fritz Graebner (1877-1934) y Wilhelm Schmidt (1868-1954), estos dos últimos impulsores de la escuela histórico-cultural. Asimismo, toma como base de su argumento propuestas contemporáneas como la de Joseph Vendryes (1875-1960), alumno Meillet; y de Alfred Kroeber (1876-1960), sucesor de Franz Boas (1858-1942). La estrategia de respaldarse en estos autores le permite cuestionar el supuesto conocimiento actualizado de Costa Álvarez, ya que estos investigadores, más recientemente que Meillet, habían planteado la posibilidad de establecer correlaciones sobre la base de otros elementos de las lenguas además de la gramática:

Con todo, las objeciones que han sido hechas al método gramatical, limitan su importancia mucho más de lo que Meillet supone. Según Vendries [sic] nada garantiza la continuidad de la morfología; el método morfológico resulta inocuo en los casos de hibridación estructural y poco útil cuando se estudian las relaciones de lenguas muy alejadas en el tiempo, en las cuales los posibles vínculos morfológicos, pueden tornarse débiles y cuestionables hasta el punto de resultar inciertos; tampoco resulta eficaz el método en las lenguas sin gramática, en las cuales toda la morfología reside en los procedimientos inmateriales de combinación de palabras aisladas (Vendries [sic] 362-364). Pero el que ha puesto particularmente de relieve las ambigüedades que implica el método gramatical, es Kroeber, quien ilustra con numerosos ejemplos tomados de las lenguas californianas toda su argumentación. (Palavecino, 1928a: 67)

Sin embargo, si bien es cierto que Vendryes (1950 [1923]) menciona situaciones en las que es admisible la comparación léxica, fundamentalmente en los casos de "lenguas sin gramática" o sin documentación, lo que Palavecino no menciona es que este autor declara que esta operación es un "proceso peligroso" (1950 [1923]: 364), por la misma razón de que puede tratarse de un caso de contacto. Kroeber, por su parte, en efecto mucho más empático con los antropólogos y conocedor de primera mano de los avatares de este tipo de investigaciones, sí admite, en el caso de estudios etnológicos o históricos, la posibilidad de establecer vínculos filogenéticos a partir de la coincidencia de elementos léxicos, tal como refiere Palavecino. Sin embargo, para 
Kroeber esto es admisible cuando el investigador no cuenta con mayor cantidad de información, ya que argumenta- las coincidencias pueden deberse a un caso de contacto (Kroeber, 1913).

Además de la cita de autoridad, el otro argumento utilizado por Palavecino es el de la cantidad de coincidencias halladas como prueba para establecer las correlaciones:

[...] en presencia de analogías de vocablos entre dos lenguas, la explicación del hecho por coincidencia fortuita, es sólo lícita cuando su número es muy limitado; pero si la cantidad de vocablos análogos sobrepasa cierto límite, la interpretación del vínculo genético se impone; por lo menos en cuanto a las correspondencias halladas. (Palavecino, 1928a: 69)

Por su parte, Imbelloni, en el artículo en respuesta a la crítica de Costa Álvarez, defiende su planteo sobre la base de los aportes de los principales exponentes de la tradición antropológica norteamericana anclada en el Bureau of American Ethnology del Smithsonian Institute, quienes habían arriesgado tipologías basadas en elementos léxicos. Es así que menciona las clasificaciones sobre las lenguas de la América septentrional de John Wesley Powell (1834-1902), quien fuera el primer director del Bureau; los trabajos de Boas y de sus discípulos Edward Sapir (1884-1939), Paul Radin (1883-1959), Roland Dixon (1875-1934) y, nuevamente, Kroeber:

El hecho es que más tarde, es decir, en estos últimos años, una pléyade de lingüistas norteamericanos han recurrido al mismo método, a saber, a la comparación léxica, para establecer nuevos parentescos, a veces entre lenguajes ampliamente distanciados por el espacio. Estas investigaciones llevan los sellos de Eduardo Sapir, y fueron conducidas a término por Radin, Dixon y Kroeber, llegándose en varios casos a comprobar la unidad de miembros muy dispersos, como ocurre con la reconocida unidad del grupo Na-dene. (Imbelloni, 1928: 375-376)

Respaldado por estos trabajos, Imbelloni plantea que la comparación léxica se justifica o por la insuficiente cantidad de datos de los planos gramatical y fonético con que cuentan los investigadores de lenguas indígenas o porque, en algunos casos, las coincidencias léxicas son más evidentes que las otras.

La referencia a Boas, además, es central en el argumento de Imbelloni por su caracterización de la realidad lingüística americana como poseedora de una "curious condition" (Boas, 1920; citado en Imbelloni, 1928a), en el sentido de que, por lo general, las correlaciones entre los distintos niveles lingüísticos en las lenguas indígenas no siempre coincidirían; es decir, la distribución de correlaciones fonéticas, por ejemplo, no necesariamente se correspondería con similitudes halladas en los planos léxico y gramatical. Este planteo lleva a Imbelloni a afirmar que las relaciones genéticas entre estas lenguas "no pueden resolverse con la adaptación mecánica de las reglas deducidas por la experiencia de las familias clásicamente célebres del viejo mundo" (Imbelloni, 1928a: 376-377).

Por último, resulta llamativa la escasez de referencias a Rivet presentes en las respuestas de Imbelloni y Palavecino. Esto posiblemente se explique porque, también en 1928, en el marco de un homenaje a Wilhelm Schmidt en Viena, al que asisten tanto Rivet como Imbelloni, se produce un nuevo debate sobre este tema. Durante su exposición, Rivet cuestiona las correlaciones e hipótesis de Imbelloni, aunque con un argumento de otro orden, distinto al cuestionamiento metodológico de Costa Álvarez ${ }^{4}$.

Bajo la mirada de investigadores europeos y tras la crítica de Costa Álvarez, es posible que Imbelloni y Palavecino se hayan visto en la necesidad de repensar y reformular sus planteos originales. Así, dos años después de la publicación de La Esfinge, los responsables de las correlaciones relativizan la comunidad de origen entre incas y polinesios y barajan la posibilidad de que, en efecto, estas consistan en una huella del contacto. Así, en la segunda respuesta de Palavecino a Costa Álvarez, aquel dirá: "En lo que se refiere a mis correlaciones, es el caso de declarar que para mí, no indican una afinidad lingüística esencial entre el kichua y el maorí, sinó [sic] simples préstamos" (Palavecino, 1928b: 425). Imbelloni, por su parte, en una carta privada que le envía a Costa Álvarez plantea una idea similar mediante la cual relativiza el supuesto parentesco: "Yo no busco, en sustancia, demostrar que el Kichua procede del sistema lingüístico Polinesio, sinó $[s i c]$ que en la formación de su vocabulario ha influido notablemente el patrimonio lingüístico de las islas del Océano" (Imbelloni, 1928b). 
En términos historiográficos, en el material se puede leer una discusión situada en Argentina sobre los métodos para el establecimiento de relaciones filogenéticas que se relaciona con discusiones que se estaban produciendo a nivel mundial. No casualmente, entre 1913 y 1928, en distintas revistas especializadas de Europa, toma lugar un debate entre el propio Meillet y Schuchardt sobre el método más adecuado para realizar tipologías lingüísticas (Baggioni, 1988). Por otra parte, por esos años, desde Estados Unidos, Boas les plantea a sus discípulos la potencialidad de la lingüística para explicar ciertos aspectos de las culturas por su funcionamiento inconsciente, marcando, así, el valor instrumental de la lingüística para responder a las preguntas de la antropología (Duranti, 2003).

Estos problemas emergen también en el ámbito local y son los pilares de la discusión. Así, Costa Álvarez, desde el lugar de la lingüística, juzga el planteo de Imbelloni y Palavecino sobre la base de la tradición lingüística francesa, fundamentalmente a partir de la propuesta de Meillet. Los americanistas, por su parte, le responden desde la antropología y entroncan sus trabajos, por un lado, en las tradiciones antropológicas difusionistas alemana (encabezada por Schmidt y Graebner), norteamericana (representada por Kroeber, principalmente) y francesa (con Rivet como su referente más destacado); como así también en la teoría alemana Wörter und Sachen (cuyos principales representantes fueron Schuchardt y Meringer). Tal como hemos visto para el caso de Kroeber e Imbelloni, en el periodo se acepta la idea de que los problemas antropológicos admiten otras prácticas metodológicas en cuanto al tratamiento de las lenguas, siempre que estas sirvan para responder a las preguntas formuladas en ese ámbito. Es justamente en este sentido que se debe leer la propuesta de Imbelloni que se verá a continuación de distinguir la emergencia de una nueva disciplina, la "etnología lingüística", que es, en definitiva, la "antropología lingüística" que se venía gestando en Estados Unidos, o la "etnolingüística” europea (Cardona, 1994; Duranti, 2000), cuyos principales exponentes son los mismos autores que cita Imbelloni.

\section{ETNOLOGÍA LINGÜÍSTICA Y LINGÜÍSTICA}

El debate en cuestión, como se anticipó anteriormente, da cuenta del proceso de conformación de distintos campos de las ciencias sociales y humanas que tuvo lugar a principios del siglo XX en Argentina. En este sentido, el comienzo de la profesionalización de la filología suele vincularse con la creación, en el año 1922, del Instituto de Filología, dependiente de la Facultad de Filosofía y Letras de la Universidad de Buenos Aires (Di Tullio, 2003; Toscano y García, 2009, 2013b); mientras que, para el caso de las ciencias antropológicas, los acontecimientos que se destacan son la creación del Museo Etnográfico de esa misma Facultad en el año 1904 y el traslado del Museo de La Plata a la naciente Universidad Nacional de La Plata en 1906, como así también la realización del Primer Congreso Científico Internacional Americano, organizado por la Sociedad Científica Argentina, y del XVII Congreso internacional de americanistas en el marco de las celebraciones por el centenario de la Revolución de Mayo (García, 2005; Perazzi, 2011; Podgorny, 2004, 2005).

Es así que la nota de Costa Álvarez publicada en La Prensa dialoga con otras polémicas por él mismo impulsadas mediante las que disputa una posición de peso dentro del naciente campo de la lingüística nacional. De hecho, es posible que, al crearse el ya mencionado Instituto de Filología, esperase ser nombrado su director por considerarse a sí mismo como el único especialista en lingüística del país (véase Costa Álvarez, 1922). Sin embargo, marginado posiblemente por autodidacta y en el marco de recomposición de las relaciones con España que tuvo lugar en la década del veinte, el cargo le es otorgado a los filólogos del Centro de Estudios Históricos de Madrid tras la alianza de Ricardo Rojas con Ramón Menéndez Pidal. A partir de allí, Costa Álvarez se convertirá en uno de los principales críticos del Instituto (Toscano y García, 2013a).

Por su parte, también el tono de La Esfinge debe ser leído en esta clave. Imbelloni, un “recién llegado" (en el sentido de Bourdieu (2000 [1976])), formado en Europa (con todo el prestigio que eso supone en el periodo), publica un libro mediante el cual no solo polemiza con varios intelectuales de peso en Argentina y cuestiona teorías consensuadas, métodos y objetivos, sino que, además, disputa la definición acerca de lo que es y no es 
el americanismo. Precisamente, esta definición será uno de los temas abordados en el debate, lo que resulta sintomático del estado en formación de los distintos campos: El Americanismo, o Americanística como escriben algunos, entre ellos Lenz, es una ciencia sui generis. No es el americanismo
astronomía, y sin embargo ha producido demostraciones o teorías astronómicas, que, al admitirlas o rechazarlas, reclaman
ser discutidas ab imo. No es el Americanismo geología, y sin embargo reposa en la geología; ni es zoología, paleontología o
botánica, pero contiene, a la vez, todo esto. De igual manera, no se puede abordar su historia, sin tener ideas claras sobre
la eficacia del método etimológico, la historia de las religiones, las ciencias orientales, la egiptología, las lenguas clásicas y la
filología. Por otra parte, su contenido esencial pertenece al antropólogo, al arqueólogo, al lingüista y al etnógrafo. (Imbelloni,
1926: 9)

Es a raíz de esta multiplicidad de temáticas y disciplinas que, en teoría, maneja un americanista, que Costa Álvarez, en su nota, no sin ironía, va a decir:

Inmenso es, pues, el acervo de hechos y de indicios de hechos que acumula en su mente para relacionarlos y explicarlos el investigador de este género, a quien llamaré aquí "arqueólogo" para simplificar su denominación; aunque este término, tan comprensivo en lo antiguo, es insuficiente hoy día para significar la masa entera de "omni re scibili" que caracteriza a estos émulos modernos de Pico de la Mirándola. (Costa Álvarez, 1928a: 15)

El hecho de encasillar a Imbelloni en el ámbito de la arqueología y no de la americanística (cuando, de hecho, hacia el final de la nota, Costa Álvarez sí engloba a este grupo con esta última etiqueta) es uno de los puntos que dan pie a la polémica.

La ya referida respuesta de Vega, quien actúa en defensa de los americanistas, se centra en este aspecto: gran parte de su intervención consiste en definir el alcance del americanismo y los límites de las disciplinas que lo componen. En relación con la clasificación de Costa Álvarez, Vega, entonces, plantea lo siguiente:

Dice luego [Costa Álvarez], que no sabe cómo llamar a personas cuya mentalidad abarca tantas disciplinas. Resuelve, por fin, llamarles "arqueólogos", para simplificar, pero convencido de que ese término es insuficiente. Yo también lo creo así. Sobre todo cuando el uso ha consagrado para el caso un vocablo que el señor Costa Álvarez emplea muy a menudo: "americanista". (1928: 50)

Desde una perspectiva similar, Imbelloni, en el comienzo de su artículo, introducirá una distinción disciplinar entre la acción de los "filólogos, lingüistas romanistas", y los encargados del estudio de las lenguas indígenas:

Ella [la de Costa Álvarez] es simplemente la posición que corresponde a una cultura esencialmente escolástica, la del lingüista puro. Conocemos esta clase de egoísmos científicos, el del geógrafo puro, el filósofo puro, etc. A un lingüista de tal naturaleza nada le interesa lo que sucede a su lado. Es algo de la sublime atonía de Arquímides. ¿Que hay un problema del autoctonismo o inmigracionismo americano? Son asuntos extraños al problema de clasificar las lenguas, o, por lo menos, no inmediatamente dependientes. Esta tendencia egoística llegó a producir la fórmula extravagante de Ferdinand de Saussure, para lo cual los hechos de la lengua deben exclusivamente servir al conocimiento de la lingüística, con la que se condena toda tentativa de sacar de tales documentos humanos la inepreciable $[s i c]$ cosecha que ofrecen a la historia, a la sociología, a la etnología y a la filosofía natural. (Imbelloni, 1928a: 378-379)

Como se lee en la cita, el interés de los etnólogos por la lingüística radica en que este tipo de conocimiento les permite resolver otro orden de problemas de corte histórico, sociológico, etnológico y filosófico. De hecho, en el mismo artículo, Imbelloni dirá que, para los etnólogos, "hay un interés muy superior [que para los lingüistas], el de discernir el autoctonismo o la alofilía de los indianos y de su cultura, cuya parte integrante son justamente las lenguas" $(377)^{5}$.

Además de los propósitos distintos que persiguen etnólogos y lingüistas, hay otra diferencia que puede recuperarse en los documentos en cuanto a los objetos de análisis. Los americanistas se encargan de las lenguas de "pueblos incultos"; por oposición, lingüistas o filólogos, por lo general, se dedican a las lenguas "de cultura”; es decir, la distinción se establece sobre la base no de características propias de las lenguas sino de 
los pueblos que las hablan (y, asociado con ello, según una práctica cultural distintiva: la escritura, como se verá a continuación). Así, Imbelloni dirá:

Entiendo hablar del empleo de esta ciencia en la magna obra cuyo fin es el conocimiento del indio americano. Es muy natural
que en esta tarea resulte escasa la contribución del filólogo, pues trata principalmente de lenguas de pueblos incultos; de ahí
la necesidad de apartarse de la senda de los lingüistas que actúan en nuestro ambiente, que son esencialmente romanistas.
Uno solo de ellos, Rodolfo Lenz, mente preclara y trabajador infatigable, ha logrado separar con método riguroso la doble
dirección de sus desvelos, y, conservando por una parte una posición elevadísima en los estudios romances, ha ilustrado
algunas lenguas sudamericanas en trabajos realmente modernos. (Imbelloni, 1928a: 373)

La referencia a Rodolfo Lenz (1863-1938) es otro aspecto de relevancia de este fragmento. Considerado como "el introductor de la lingüística moderna en América Latina" (Ennis, 2012: 183), la figura de Lenz es clave en la tradición de estudios sobre lenguas indígenas americanas, ya que es uno de los pocos (si no el único) lingüistas de la región, formado en esta materia, que se ocupa de estas lenguas -fundamentalmente del mapudungun- (Ennis, 2016), un objeto desestimado por filólogos y lingüistas que es absorbido, en consecuencia, por los especialistas en el estudio del otro cultural, los encargados de dilucidar los "enigmas americanos”, siguiendo la metáfora de Imbelloni. Así, exceptuando el caso de Lenz, la lingüística aparece como una disciplina ocupada por el problema de las lenguas de tradición escrita, las "lenguas de cultura", que son, precisamente, las lenguas de los estados modernos. En este sentido, la tradición generalmente oral de las culturas indígenas y la escasez de registro documental terminan siendo un impedimento técnico para la lingüística (Cardona, 1994). Costa Álvarez, en este mismo sentido, dirá:

Tremenda empresa es la de reconstruir históricamente la vida de la humanidad en los tiempos anteriores a la escritura, es decir, al registro de los hechos contemporáneos; a falta de esta base el investigador de la prehistoria tiene que buscar sus materiales de estudio en todos los terrenos en que existan reliquias de esos tiempos remotos, para tratar de descubrir, a través de ellas, la evolución psíquica de la humanidad en sus primeras manifestaciones. (Costa Álvarez, 1928: 15)

Si bien a fines del siglo XIX en Argentina (y en el mundo) se había comenzado a hacer trabajos etnográficos de documentación de estas lenguas con una mayor sistematicidad y de manera independiente de la empresa misional de la Iglesia, a comienzos del siglo XX se registran pocos trabajos de elicitación en el campo. De hecho, Imbelloni y casi todos los investigadores de la época de este país (exceptuando algunos casos como el de Lehmann-Nitsche) hacen del estudio de las lenguas indígenas un trabajo de gabinete, sobre la base del material documental con el que ya cuentan, que son, mayoritariamente, registros léxicos (tal es el caso de las correlaciones de Imbelloni y el vocabulario comparado de Palavecino, cuyo principal insumo son los diccionarios de las lenguas en cuestión), aun existiendo la posibilidad de hacer etnografía, sobre todo considerando el lugar geográfico privilegiado de los americanistas locales por la cercanía con distintos pueblos indígenas.

Por otra parte, esta distribución del tipo de lenguas de las que se encargan lingüística y antropología respectivamente, basada en su tradición oral o escrita, irremediablemente impacta en la definición y el lugar histórico en que se ubica al otro cultural (Bauman y Briggs, 2003). En este sentido, este reparto epistemológico, al que adhieren incluso a pesar de sus diferencias más evidentes todos los participantes en este debate, implica el emplazamiento de lenguas y pueblos indígenas en el segmento temporal de la "prehistoria" del territorio nacional, tiempos indocumentados, donde hombre y naturaleza se confunden, situación que contrasta con las sociedades modernas, las que, mediante el conocimiento científico, han logrado distinguir naturaleza de sociedad (Latour, 2012 [1993]). De allí que el "indio" sea ubicado en el mismo plano de intereses que la flora y la fauna, en tanto parte del paisaje natural. En este esquema, entonces, si la lingüística se encarga del estudio de las lenguas de cultura, las lenguas de los modernos estados-nación, la antropología forma parte de la construcción de la "enigmática" "prehistoria” del territorio del país. Es así que, tal como plantea Ennis (2012: 191), "[e]l otro, que recibe la atención, comprensión y compasión del científico, no lo 
hace sino en condición de objeto arqueológico, de archivo filogenético de la humanidad o la nación según el caso, lugar del secreto que debe ser descifrado, y en última instancia, sustraído"6.

Esta opción metodológica se explica, además, por otra razón, que también se traduce en la temporalidad en la que son inscritos discursivamente estos pueblos. Así, al momento de la polémica, el de las lenguas indígenas es considerado un problema del pasado, ya casi saldado por completo después de las campañas de exterminio que tomaron lugar entre las décadas del setenta y ochenta del siglo XIX. Por su parte, las emergentes ciencias del lenguaje tienen una situación mucho más crítica y apremiante por resolver: el peligro de la integridad y pureza del español frente al fenómeno de inmigración masiva proveniente principalmente de Italia, ya que se pensaba que la hegemonía de la lengua nacional se encontraba en franca amenaza (Di Tullio, 2003; López García, 2009).

En síntesis, frente a este tipo de diferencias de objeto (lenguas con y sin tradición escrita) y epistemológicas a la hora de analizar lenguas por parte de antropólogos y filólogos o lingüistas, Imbelloni, en su respuesta a Costa Álvarez, propone una disciplina, la "etnología lingüística”, que, si bien tiene reminiscencias de la antropología lingüística norteamericana en emergencia, en definitiva no es sino una etnología de las lenguas, donde "lingüística" operaría como un simple adjetivo de la nueva etiqueta:

\footnotetext{
Hay, pues, una etnología lingüística, y si no es ya recomendable clasificar los pueblos y sus grupos con el criterio de las grandes lenguas como intentó Müller, nos queda en cambio el deber de tener en cuenta uno de los más preclaros fenómenos culturales, como es la lengua, al trazar la historia y el camino de las culturas, y de ello ha nacido la obra lingǘstica de Schmidt, que es también maestro de una generación de etnólogos. A veces también el etnólogo sigue un método del todo propio, empleando los vocablos como simple elemento cultural, o en connexión [sic] con el objeto que el mismo indica, y cambiando de examen de forma del vocablo y del objeto, lo que se llama el conjunto de Wörter und Sachen. (1928a: 379)
}

En este esquema, en el que los límites disciplinares iban cobrando mayor nitidez, el estudio de las lenguas indígenas era un conocimiento que permanecía en los bordes. Si bien eran, en su gran mayoría, intelectuales abocados a las ciencias antropológicas los encargados de su documentación y análisis, la naturaleza del objeto llevaba a lingüistas y filólogos a presentarse como los legítimos capacitados para cuestionar el método aplicado por antropólogos para su tratamiento ${ }^{7}$. Estas son las condiciones en que Costa Álvarez pone en cuestión la multiplicidad de disciplinas que se interrelacionan en el trabajo de Imbelloni, quien no era un especialista en lingüística.

Del mismo modo, el "egoísmo científico" que menciona Imbelloni en la cita más arriba debe ser leído en esta clave. En un mundo donde el conocimiento científico iba en vías de compartimentarse en áreas con un funcionamiento relativamente autónomo, la propuesta de Imbelloni sería considerada, cuanto menos, polémica. Así, el proceso por el que atraviesa la ciencia de delimitar objetos, confeccionar métodos específicos y establecer lógicas propias de legitimación es amenazante para el americanismo, un área de estudios deudora del siglo XIX, concentrada en unos pocos individuos que se valen de las herramientas y descubrimientos de distintos ámbitos del conocimiento: desde egiptología hasta botánica, pasando por antropología, arqueología y lingüística ${ }^{8}$.

\section{Conclusiones}

A partir de una nota firmada por Costa Álvarez en el diario La Prensa en 1928 se desencadenó un debate donde participaron Imbelloni y Palavecino (y, en menor medida, Vega). La discusión giró en torno al método aplicado por los americanistas para el tratamiento de las lenguas indígenas, lo que nos permitió caracterizar algunos aspectos fundamentales sobre el lugar otorgado a estas lenguas dentro del campo científico no solo nacional sino también internacional en las primeras décadas del siglo XX. Así, la lectura del debate habilita retomar las principales discusiones que se estaban dando en Europa y Estados Unidos sobre el tema, por un lado. Por el otro, posibilita dar cuenta de la emergencia de dos campos científicos distintos, el de la 
lingüística y el de la antropología, y la situación fronteriza en que quedan las lenguas indígenas, no tanto por sus características intrínsecas, sino por una cuestión técnica de los análisis lingüísticos centrados en registros escritos y, a su vez, por los problemas de los que se ocupa el americanismo, donde el estudio de estas lenguas tendrá un papel clave, aunque no será una preocupación central.

\section{BibLIOGRAFía}

Alfón, F. (2011). La querella de la lengua argentina (1828-1928). (Tesis doctoral). Universidad Nacional de La Plata, La Plata, Argentina.

Baggioni, D. (1988). Le débat Schuchardt / Meillet sur la parenté des langues (1906-1928). Histoire Épistémologie Langage, 10(2), 85-97.

Bauman, R. y Briggs, Ch. L. (2003). Voices of Modernity. Language Ideologies and the Politics of Inequality. New York: Cambridge University Press.

Benigar, J. (1928). El problema del hombre americano. Bahía Blanca: Panzini hnos.

Bourdieu, P. (2000). Los usos sociales de la ciencia. Buenos Aires: Nueva visión.

Boas, F. (1920). The classification of american languages. American anthropologist, 22, 367-376.

Bruno, P. (2012). Vida intelectual de la Argentina de fines del siglo XIX y comienzos del XX. Un balance historiográfico. PolHis, 5(9), 69-91.

Calvo Calvo, L. (1991). Fritz Krüger y los filólogos del 'Seminario de Lengua y Culturas Románicas' de la Universidad de Hamburgo. Sus aportaciones de la etnografía peninsular. Revista de Dialectología y Tradiciones Populares, 46, 349-361.

Cardona, G. (1994). Lenguajes del saber. Barcelona: Gedisa.

Costa Álvarez, A. (1922). Nuestra lengua. Buenos Aires: Sociedad Editorial Argentina.

Costa Álvarez, A. (1928a). La lingüística al uso del arqueólogo. La Prensa, 15.

Costa Álvarez, A. (1928b). La lingüística al uso del arqueólogo. Nosotros, XXII(234), 280-282.

Costa Álvarez, A. (1929). La lingüística al uso del arqueólogo. Nosotros, XXIII(236-237), 155-156.

Degiovanni, F. y Toscano y García, G. (2010). 'Las alarmas del doctor Américo Castro’: institucionalización filológica y autoridad disciplinaria. Variaciones Borges, 30, 3-41.

Di Tullio, Á. (2003). Politicas lingüisticas e inmigración. El caso argentino. Buenos Aires: EUDEBA.

Domínguez, L. (2017). La participación de José Imbelloni en Toponimia patagónica de etimología araucana (1950) de Juan Domingo Perón. En III Jornadas de Jóvenes Lingüistas, del 26 al 28 de julio de 2017, Ciudad de Buenos Aires, Argentina.

Duranti, A. (2000). Antropología lingüistica. Madrid: Cambridge University Press.

Duranti, A. (2003). Language as Culture in U.S Anthropology; Three Paradigms. Current anthropology, 44, 323-347.

Ennis, J. (2012). Rudolf Lenz en la encrucijada criolla. Signo y seña, 22, 181-214.

Ennis, J. (2016). Rodolfo Lenz: economías de la lengua y políticas de la lingüística. Boletín de fllología, LI(1).

García, S. (2005). Discursos, espacios y prácticas en la enseñanza científica de la universidad platense. Saber y tiempo, $20,19-62$.

Imbelloni, J. (1926a). La Esfinge Indiana. Antiguos y nuevos aspectos de los origenes del hombre americano. Buenos Aires: El Ateneo.

Imbelloni, J. (1926b). Nuevos estudios del quechua. El idioma de los incas en el sistema lingüístico de Oceanía. Boletín de la Junta de Historia y Numismática Americana, III, 29-49.

Imbelloni, J. (1928a). Etnología y lingüística. Nosotros, XXII(235), 373-381.

Imbelloni, J. (1928b). Carta a Arturo Costa Álvarez. Fondo Arturo Costa Álvarez, Biblioteca Pública de La Plata. 
Imbelloni, J. (1930). Nómina de publicaciones relacionadas con las ciencias del hombre (1921-1930). Buenos Aires: Talleres gráficos de Porter hnos.

Imbelloni, J. (1943). Concepto y praxis del folklore como ciencia. Buenos Aires: Editorial Humanior.

Korsbaek, L. (2003). La antropología y la lingüística. Ciencia Ergo Sum, 10(2), 159-172.

Kroeber, A. (1913). The determination of Linguistics Relationship. American Anthropologist, 1903, 1-26.

Latour, B. (2012). Nunca fuimos modernos. México: Siglo XXI.

López García, M. (2009). Discusión sobre la lengua nacional en Argentina: posiciones en el debate y repercusiones en la actualidad. Revista de Investigación Lingüistica, 12, 375-397.

Mailhe, A. (2016). Polémicas ideológicas en la antropología argentina: el americanismo cientificista de la Biblioteca Humanior. En IX Jornadas de Sociología de la UNLP, del 5 al 7 de diciembre de 2016, Ensenada, Argentina. Recuperado de: http://www.memoria.fahce.unlp.edu.ar/trab_eventos/ev.8839/ev.8839.pdf

Meillet, A. (1913). Sur la méthode de la grammaire comparée. Revue de métaphysique et de morale, 21(1), 1-15.

Meillet, A. (1924). Avant propos. En A. Meillet y M. Cohen (eds.), Les langues du monde (pp. VII-X).Paris: Librairie Ancienne Édouard Champion.

Palavecino, E. (1926). Elementos lingüísticos de Oceanía en el Quechua. En J. Imbelloni (ed.), La Esfinge Indiana. Antiguos y nuevos aspectos de los origenes del hombre americano (pp. 335-349). Buenos Aires: El Ateneo.

Palavecino, E. (1928a). Los orígenes americanos y la lingüística. (A propósito de una doctrina sobre el parentesco de las lenguas). Nosotros, XXII(233), 65-72.

Palavecino, E. (1928b). Sobre los orígenes americanos y la lingüística. Nosotros, XXII(235), 423-425.

Palavecino, E. (1929). Todavía los orígenes americanos y la lingüística. Nosotros, XXIII(238), 294-295.

Perazzi, P. (2009). La recepción de la 'escuela histórico-cultural' en la antropología argentina. En V Jornadas de Historia de las Izquierdas, del 11 al 13 de noviembre de 2009, Ciudad de Buenos Aires, Argentina, 45-60.

Perazzi, P. (2011). La antropología en escena: redes de influencia, sociabilidad y prestigio en los orígenes del Museo Etnográfico de la Universidad de Buenos Aires. Anthropologica, XXIX(29), 215-231.

Perna, C. G. (2007). Palabras y cosas: un recorrido por su historia como escuela y como método de la dialectología románica. Romanisches Seminar, Ruppert-Karls-Universität Heidelberg.

Podgorny, I. (2004). 'Tocar para creer'. La arqueología en la Argentina, 1910-1940. Anales del Museo de América, 12, $147-182$.

Podgorny, I. (2005). La derrota del genio. Cráneos y cerebros en la filogenia argentina. Saber y tiempo, 20, 63-106.

Ratier, H. (2010). La antropología social en Argentina: su desarrollo. Publicar, VIII(IX).

Rivet, P. (1924a). Les Mélanéso-Polynesiens et les Australiens en Amérique. Bulletin de l'Académie des sciences, inscriptions et belles-lettres du Paris, 68(5), 335-342.

Rivet, P. (1924b). Langues amèricaines. En A. Meillet y M. Cohen, Les langues du monde (pp. 597-712). Paris: Librairie Ancienne Édouard Champion.

Rivet, P. (1925). Les origines de l'homme américain. L'anthropologie, XXXV, 293-319.

Rivet, P. (1928). Relaciones comerciales precolombinas entre Oceanía y América. Anales de la Facultad de Ciencias de la Educación (Universidad Nacional del Litoral), III, 165-193.

Sesnich, L. (2014). Reflexiones sobre la lengua en la prensa cultural argentina: el caso de la revista Nosotros (1907-1920). Revista argentina de historiografia lingüistica, VI(1), 73-88.

Toscano y García, G. (2005). Amado Alonso en Argentina: un problema de campo. En S. Santos y J. Panesi (coords.). Debates actuales. Las teorias criticas de la literatura y la lingüistica. Buenos Aires: Universidad de Buenos Aires.

Toscano y García, G. (2013a). Debates sobre la lengua e institucionalización filológica en la Argentina durante la primera mitad del siglo XX. En J. Del Valle, Historia politica del español. La creación de una lengua (pp. 245-265). Aluvión: Madrid.

Toscano y García, G. (2013b). Materiales para una historia del Instituto de Filología de la Universidad de Buenos Aires (1927-1946). Filología, XL, 143-172. 
Vega, C. (1928). Costa Álvarez y la Americanística. Nuestras escuelas, II(11-12), 49-52.

Vendryes, J. (1950) [1923]. Le langage. Introduction linguistique à l'histoire. París: Éditions Albin Michel.

\section{Notas}

1 En 1936, toman lugar cuatro acontecimientos que terminan por ubicar a Imbelloni en el centro del campo antropológico nacional: primero, la publicación de Epitome de culturología, una obra donde expone los principales lineamientos de la escuela histórico cultural germana a la que adscribe, que será predominante en los estudios locales hasta los primeros años de la década del sesenta, cuando el estructuralismo se instala definitivamente en este país y cuando egresa la primera camada de estudiantes de las nuevas carreras de antropología de las universidades de Buenos Aires y La Plata (Ratier, 2010). Este libro, a su vez, constituye el lanzamiento de una ambiciosa colección de obras sobre variados temas del americanismo, la "Colección Humanior. Biblioteca del Americanista Moderno". Imbelloni, además de desempeñarse como su director, interviene como autor o coautor en la mayoría de las publicaciones. En tercer lugar, también en 1936, colabora con la monumental Historia de la Nación Argentina, con dos artículos, uno referido a las lenguas indígenas del territorio argentino y otro sobre las etnias fueguinas. Finalmente, es de particular relevancia en su carrera la participación como miembro fundador de la Sociedad Argentina de Antropología en 1936, en la que se designado Director de publicaciones (Domínguez, 2017).

2 El carácter polémico de esta publicación lo puso en la mira de muchos intelectuales de distintas partes del mundo. El caso más extremo es el de Juan Benigar (1883-1950), un estudioso croata radicado en Kelleñ Ko, provincia de Neuquén, quien dedicó un libro completo a la crítica de La Esfinge, titulado El problema del hombre americano, que también será objeto de la crítica de Costa Álvarez en el mismo artículo de La Prensa. Allí, Benigar remarca, entre muchas otras cuestiones, la estrategia de Imbelloni para publicitar su libro a partir de la cantidad de intelectuales a los que expresamente se opone (Benigar, 1928: 8).

3 Resulta destacable que, al mismo tiempo que Meillet es la base de su argumento, Rivet sea uno de los blancos de su crítica, sobre todo considerando que este había sido el encargado de la sección "Langues Américaines" de Les langues du monde, organizada, precisamente, por Meillet y Marcel Cohen y publicada en 1924. En la introducción de la sección a su cargo, de cualquier forma, Rivet plantea una objeción similar a la de Imbelloni en cuanto a la dificultad de trabajar con estas lenguas por la escasa documentación de la que se dispone; también menciona el hecho de que, en su sección, habrá casos de vínculos lingüísticos basados en el vocabulario debido a la ausencia de correlaciones gramaticales (tal es el caso de las otras correlaciones mencionadas anteriormente, también basadas en correspondencias léxicas), situación que lamenta y de la que responsabiliza al estado de desarrollo de los estudios de lenguas indígenas en América: "Cette grave lacune de la linguistique américaine tient surtout à la valeur très inégale des matériaux que l'on possède sur chaque dialecte; elle provient aussi de ce fait que les langues américaines n’ont été l'objet de travaux sérieux que depuis peu d'années, et que, trop souvent, les personnes qui s'y consacrent n'ont ni la culture générale ni la discipline scientifique des linguistes qui se sont spécialisés dans l'étude des langues du vieux continent" (Rivet, 1924: 603).

4 Para Rivet, la naturaleza de esta conexión respondería a vínculos comerciales precolombinos entre los pueblos polinesios y americanos. A su vez, plantea que la distribución de los términos provenientes de las islas sería desigual en las distintas lenguas americanas que eran objeto de comparación, lo que le permite debilitar el planteo de Imbelloni fundamentalmente por tratarse de apariciones no tan frecuentes, en lenguas pertenecientes a grupos muy distintos-: "Tales son los datos lingüísticos sobre los que quería llamar la atención. Observamos que no pueden interpretarse como una prueba de parentesco del Kichua y del Polinesio, como lo han propuesto Palavecino e Imbelloni a propósito de kumar y toki. En efecto, si kumar, kumal, pertenece realmente al Kichua, el uso de este vocablo está limitado con toda claridad al dominio septentrional de esta lengua, en tanto que la palabra toki, es exclusivamente araucana. Las dos palabras se encuentran por lo tanto en dos regiones muy distantes y en lenguas diferentes" (Rivet, 1928: 173).

5 Poco más de una década antes, Kroeber (1913) había planteado algo similar respecto de la diferencia de enfoque y aspectos entre un filólogo y un "historiador de los pueblos y las civilizaciones": "The philologist can understand the nature of a language quite thoroughly, and apperceive all its structure pretty correctly, without knowing anything as to its genetic relationship or lack of relationship with other idioms. The psychology of speech has very little to do with the history of languages. The aims, problems, and therefore methods, are distinct. On the other hand, the history of languages is of the greatest importance to the historian of peoples and civilizations" (392-393).

6 La metáfora del secreto propuesta por Ennis (2012) recupera la recurrencia en la época de considerar la problemática indígena como un enigma; lo mismo sucede con el título del libro de Imbelloni. Mediante este procedimiento se construye al "indio" como un completo desconocido, una esfinge a resolver. Una de las principales barreras entre el mundo conocido y desconocido es, precisamente, la lengua. 
7 Esta situación de marginalidad de las lenguas indígenas en el campo de la lingüística pervive hasta avanzado el siglo XX en Argentina. De hecho, no será hasta la década del sesenta, con la creación del Centro de Estudios Lingüísticos de la Facultad de Filosofía y Letras de la Universidad de Buenos Aires, que pasarán a ser un objeto de relevancia para la lingüística académica. Véase Toscano y García (2009, 2013b) para una relación del lugar que el estudio de las lenguas indígenas ocupa durante el proceso de emergencia y consolidación de un campo científico para los estudios lingüísticos.

8 Sin embargo, llevará sus pretensiones de crear un campo científico propio del americanismo hasta sus últimas consecuencias al proponerle a la Facultad de Filosofía y Letras de la Universidad de Buenos Aires, en la década del cuarenta, la creación de una carrera que se denominaría "Ciencias de América” (Imbelloni, 1943). 